\title{
Supraphysiological hyperinsulinaemia is necessary to stimulate skeletal muscle protein anabolism in older adults: evidence of a true age-related insulin resistance of muscle protein metabolism
}

\author{
S. Fujita • E. L. Glynn • K. L. Timmerman • \\ B. B. Rasmussen - E. Volpi
}

Received: 6 May 2009 / Accepted: 28 May 2009/Published online: 9 July 2009

(C) Springer-Verlag 2009

\begin{abstract}
Aims/hypothesis The physiological increase in muscle protein anabolism induced by insulin is blunted in healthy, glucose-tolerant older adults. We hypothesised that the agerelated defect in muscle protein anabolism is a true insulin resistance state and can be overridden by supraphysiological hyperinsulinaemia.

Methods We used dye dilution, stable isotopic and immunoblotting techniques to measure leg blood flow, muscle protein synthesis, protein kinase $\mathrm{B} /$ mammalian target of rapamycin (Akt/mTOR) signalling, and amino acid kinetics in 14 healthy, glucose-tolerant older volunteers at baseline, and during an insulin infusion at postprandial (PD, $0.15 \mathrm{mU} \mathrm{min} \min ^{-1} 100 \mathrm{ml}^{-1}$ ) or supraphysiologically high (HD, $0.30 \mathrm{mU} \min ^{-1} 100 \mathrm{ml}^{-1}$ ) doses.

Results Leg blood flow, muscle protein synthesis, and Akt/ mTOR signalling were not different at baseline. During hyperinsulinaemia, leg blood flow $(p<0.01)$ and muscle protein synthesis increased in the HD group only (PD [\%/ $\mathrm{h}]$ : from $0.063 \pm 0.006$ to $0.060 \pm 0.005$; $\mathrm{HD}[\% / \mathrm{h}]$ : from
\end{abstract}

S. Fujita $\cdot$ K. L. Timmerman $\cdot$ E. Volpi $(\bowtie)$

Sealy Center on Aging, University of Texas Medical Branch,

301 University Boulevard,

Galveston, TX 77555-0460, USA

e-mail: evolpi@utmb.edu

S. Fujita $\cdot$ E. Volpi

Department of Internal Medicine,

University of Texas Medical Branch,

Galveston, TX, USA

E. L. Glynn • B. B. Rasmussen

Department of Physical Therapy,

University of Texas Medical Branch,

Galveston, TX, USA
$0.061 \pm 0.007$ to $0.098 \pm 0.007 ; p<0.01)$. Muscle Akt phosphorylation increased in both groups, but the increase tended to be greater in the HD group $(p=0.07)$. The level of p70 ribosomal S6 kinase 1 (S6K1) phosphorylation increased in the HD group only $(p<0.05)$. Net amino acid balance across the leg improved in both groups, but a net anabolic effect was observed only in the HD group $(p<$ $0.05)$.

Conclusions/interpretation We conclude that supraphysiological hyperinsulinaemia is necessary to stimulate muscle protein synthesis and anabolic signalling in healthy older individuals, suggesting the existence of a true age-related insulin resistance of muscle protein metabolism.

Keywords Ageing - Insulin - Insulin resistance · Muscle protein synthesis $\cdot$ Sarcopenia
Abbreviations
Akt Protein kinase B
eEF2 Eukaryotic elongation factor 2
FSR Fractional synthetic rate
ICG Indocyanine green
mTOR Mammalian target of rapamycin
S6K1 p70 ribosomal S6 kinase 1
USC University of Southern California, Los Angeles
UTMB University of Texas Medical Branch at Galveston
4E-BP1 4E binding protein 1

\section{Introduction}

Physiological hyperinsulinaemia stimulates muscle protein synthesis and anabolism in young people regardless of 
glucose tolerance as long as amino acid delivery to the muscle is not decreased [1-9]. However, ageing is associated with an inability of insulin to stimulate muscle protein synthesis and net amino acid uptake in healthy, glucose-tolerant persons $[8,10]$. This defect is associated with endothelial dysfunction and a blunted mammalian target of rapamycin (mTOR) signalling, which limit muscle perfusion and protein anabolism during hyperinsulinaemic stimulation in older adults $[8,10,11]$. The decline in muscle protein anabolic response to insulin is likely to be responsible for the observed reduction in muscle protein anabolism following mixed feeding in older people [12, 13], and thus to contribute to the development of agerelated muscle loss (sarcopenia). Sarcopenia, in turn, is an important contributor to frailty and disability associated with ageing [14], and it has recently been estimated that its healthcare cost may be comparable with that of osteoporosis [15].

We have recently demonstrated that an insulinsensitising intervention, aerobic exercise, can acutely restore a normal protein anabolic response to physiological hyperinsulinaemia in older individuals with normal glucose tolerance [11], suggesting that this age-related defect shares at least some features with the classic insulin resistance of type 2 diabetes. However, the inability of muscle protein metabolism to mount an anabolic response during physiological hyperinsulinaemia in otherwise healthy older people cannot be defined as an insulin resistance state unless it is demonstrated that insulin concentrations above the physiological range can produce an anabolic effect on skeletal muscle.

The purpose of this study was to determine if exposure of skeletal muscle to insulin concentrations above the physiological postprandial range could induce a protein anabolic response in healthy older adults.

\section{Methods}

Participants We studied 14 older volunteers (11 men and three women) from the greater Galveston/Houston area and the Los Angeles metropolitan area. All individuals provided informed written consent before participating in the study, which was approved by the Institutional Review Boards of the University of Texas Medical Branch at Galveston (UTMB) and the University of Southern California, Los Angeles (USC).

All volunteers were healthy and independent (no impairment in the activities of daily living or instrumental activities of daily living), but were not engaged in an exercise training programme. Screening was performed with clinical history, physical examination and a number of laboratory tests including a $2 \mathrm{~h} 75 \mathrm{~g}$ oral glucose tolerance test. Only individuals with screening results within normal limits were randomly assigned to one of two groups receiving either a postprandial-dose (PD) or high-dose (HD) insulin infusion. The characteristics of enrolled volunteers are summarised in Table 1. This experiment was part of a larger randomised study in which young and older individuals were assigned to various treatments. Data from six volunteers in the PD group have been included in a separate report [10]. Primary outcome data (blood flow and muscle protein synthesis) obtained in young, body mass index (BMI)-matched individuals $(n=7$, age $31 \pm$ 2 years, BMI $26.2 \pm 1.4 \mathrm{~kg} / \mathrm{m}^{2}, p=\mathrm{NS}$ vs older volunteers by one-way ANOVA) undergoing the same postprandial insulin infusion experiment as the PD group are also reported.

Study design We measured blood flow, muscle protein, amino acid and glucose kinetics, and components of the protein kinase $\mathrm{B} /$ mammalian target of rapamycin (Akt/ mTOR) signalling pathway in the post-absorptive basal state $(0-5 \mathrm{~h})$ and during insulin infusion $(5-8 \mathrm{~h})$. Each volunteer was admitted to the UTMB or USC General Clinical Research Center in the afternoon prior to the infusion study. At 18:30 hours, all volunteers were fed a standardised dinner (one-third of their estimated daily energy requirements: $60 \%$ carbohydrate, $20 \%$ protein and $20 \%$ fat). They were given a snack at 22:00 hours, after which they were allowed only water ad libitum until the end of the experiment. The next morning, catheters were inserted into a forearm vein for tracer and dextrose infusion, in a contralateral hand vein for arterialised blood sampling, and in the femoral artery and vein of one leg for blood sampling. The arterial catheter was also used for infusion of insulin (Humulin R; Eli Lilly, Indianapolis, IN, USA) and indocyanine green (ICG; Akorn, Buffalo Grove, IL, USA).

Table 1 Characteristics of the older volunteers undergoing a local insulin infusion in one leg at postprandial or high dose

\begin{tabular}{llll}
\hline Characteristic & Postprandial dose & High dose & $p$ value \\
\hline Sex: male/female & $6 / 2$ & $5 / 1$ & 0.70 \\
Age (years) & $69 \pm 1$ & $72 \pm 2$ & 0.14 \\
Weight $(\mathrm{kg})$ & $83 \pm 3$ & $86 \pm 4$ & 0.56 \\
Height $(\mathrm{cm})$ & $176 \pm 4$ & $168 \pm 3$ & 0.14 \\
BMI $\left(\mathrm{kg} / \mathrm{m}^{2}\right)$ & $27 \pm 1$ & $30 \pm 1$ & 0.06 \\
Lean body mass $(\mathrm{kg})$ & $54 \pm 3$ & $56 \pm 2$ & 0.56 \\
Fat mass $(\mathrm{kg})$ & $21 \pm 2$ & $26 \pm 3$ & 0.17 \\
Leg volume $(\mathrm{l})$ & $9.3 \pm 0.4$ & $9.0 \pm 0.7$ & 0.63 \\
\hline
\end{tabular}

Data are means \pm SE 
At 07:30 hours, after drawing a blood sample to measure background phenylalanine enrichment and ICG concentration, a primed $(2 \mu \mathrm{mol} / \mathrm{kg})$ continuous infusion of $\mathrm{L}-$ [ring- ${ }^{13} \mathrm{C}_{6}$ ]phenylalanine $\left(0.05 \mu \mathrm{mol} \mathrm{kg}^{-1} \mathrm{~min}^{-1}\right.$; Cambridge Isotope Laboratories, Andover, MA, USA) was started and maintained until the end of the experiment. At $2 \mathrm{~h}$ after initiation of the stable isotope infusion, we took the first muscle biopsy from the lateral portion of the vastus lateralis of the leg bearing the femoral catheters, using a $5 \mathrm{~mm}$ Bergström biopsy needle, aseptic procedure and local anaesthesia with 1\% (wt/vol.) lidocaine injected subcutaneously and on the muscle fascia. The 150-400 mg muscle sample was quickly rinsed with ice-cold saline, blotted, and immediately frozen in liquid nitrogen and stored at $-80^{\circ} \mathrm{C}$ until analysis. During the fifth hour of tracer infusion, ICG was infused in the femoral artery $(0.5 \mathrm{mg} / \mathrm{min})$; four blood samples were taken at $10 \mathrm{~min}$ intervals from the femoral and hand veins to measure ICG concentration, after which another series of four blood samples were taken from the femoral artery and vein to measure glucose concentrations and phenylalanine concentrations and enrichments. Four additional samples were also drawn from the hand and femoral veins to measure systemic and femoral insulin concentrations, respectively. A second muscle biopsy was taken at the end of the fifth hour as previously described.

Immediately after the second biopsy, an insulin infusion was started directly into the femoral artery at the following infusion rates: $\mathrm{PD}=0.15 \mathrm{mU}_{\mathrm{min}^{-1}} 100 \mathrm{ml}^{-1}$ $\left(\sim 0.2 \mathrm{mU} \mathrm{kg}^{-1} \min ^{-1}\right) ; \mathrm{HD}=0.30 \mathrm{mU} \mathrm{min}^{-1} 100 \mathrm{ml}^{-1}$ $\left(\sim 0.4 \mathrm{mU} \mathrm{kg}^{-1} \mathrm{~min}^{-1}\right)$. This technique allowed us to avoid the remarkable reduction in blood amino acid concentrations typically seen during systemic insulin infusion $[1,16]$. A euglycaemic clamp was performed infusing 20\% (wt/ vol.) dextrose at a variable rate, which was adjusted based on blood glucose concentrations measured every 5-10 min.

During the eighth and last hour of the experiment, ICG was infused again to measure leg blood flow, and blood samples were taken to measure ICG concentrations, phenylalanine and glucose enrichments and concentrations, and insulin concentrations, as described above for the basal period. At $480 \mathrm{~min}$, before stopping the insulin and tracer infusion, a third muscle biopsy was taken as described above.

Analytical methods Plasma glucose concentration was measured using an automated enzymatic method (YSI, Yellow Springs, OH, USA), and serum ICG concentration was measured spectrophotometrically at $\lambda=805 \mathrm{~nm}$ (Beckman Coulter, Fullerton, CA, USA) $[17,18]$.

Blood phenylalanine concentrations and enrichments were determined by GC-MS (Agilent Technologies, Palo Alto, CA, USA) as previously described [19]. Phenylalanine concentration was used as a predictor of insulin- induced changes in the concentration of all essential amino acids [20].

Free amino acids and proteins were extracted from muscle tissue as previously described [19], and intracellular free phenylalanine concentrations and enrichments were determined by GC-MS as previously described [19]. Mixed muscle protein-bound phenylalanine enrichment was analysed by GC-MS after protein hydrolysis and amino acid extraction [19] using the external standard curve approach [21].

Immunoblotting was performed on $\sim 50 \mathrm{mg}$ of frozen tissue after homogenisation [22]. Total protein concentration was determined using the Bradford assay (Smartspec Plus, BioRad, Hercules, CA, USA). The supernatant fraction was diluted $(1: 1)$ in a sample buffer mixture and then boiled for $3 \mathrm{~min}$ at $100^{\circ} \mathrm{C}$, except for samples used to assay 4E binding protein 1 (4E-BP1). Samples were separated by electrophoresis (Criterion, BioRad); gels contained an internal loading control (rodent skeletal muscle) and molecular mass ladder (Precision Plus, BioRad). Proteins were then transferred to a polyvinylidene difluoride membrane (BioRad) and incubated with primary antibody overnight at $4^{\circ} \mathrm{C}$. The next morning, blots were incubated with secondary antibody for $1 \mathrm{~h}$. Chemiluminescent solution (ECL Plus; Amersham BioSciences, Piscataway, NJ, USA) was applied to each blot and optical density measurements were obtained (ChemiDoc, BioRad). Densitometric analysis was performed using Quantity One 4.5.2 software (BioRad). Membranes were stripped using Restore Western Blot Stripping Buffer (Pierce Biotechnology, Rockford, IL, USA) and reprobed for total protein. Density values were normalised to the internal loading control and data were expressed as phospho divided by total protein. Primary antibodies were purchased from Cell Signalling (Beverly, MA, USA). Phospho-specific antibody concentrations were: 1:1,000 for Akt $\left(\operatorname{Ser}^{473}\right)$, mTOR $\left(\operatorname{Ser}^{2448}\right), 4 \mathrm{E}-\mathrm{BP} 1\left(\mathrm{Thr}^{37 /}\right.$ $\left.{ }^{46}\right)$, eukaryotic elongation factor 2 (eEF2) $\left(\mathrm{Thr}^{56}\right)$; and 1:500 for phospho-p70 ribosomal S6 kinase 1 (S6K1) $\left(\mathrm{Thr}^{389}\right)$. Antibody dilutions for all total proteins were 1:1,000. Anti-rabbit IgG horseradish peroxidase-conjugated secondary antibody was purchased from Amersham Bioscience $(1: 2,000)$.

Calculations Mixed muscle protein fractional synthetic rate (FSR) was calculated using the precursor-product model to calculate the synthesis rate as follows [23]:

$\mathrm{FSR}=\left(\Delta E_{\mathrm{p}} / t\right) /\left[\left(E_{\mathrm{M}(1)}+E_{\mathrm{M}(2)}\right) / 2\right] \times 60 \times 100$

where $\Delta E_{\mathrm{p}}$ is the increment in protein-bound phenylalanine enrichment between two sequential biopsies, $t$ is the time between the two sequential biopsies, $E_{\mathrm{M}(1)}$ and $E_{\mathrm{M}(2)}$ are 
the phenylalanine enrichments in the free intracellular pool in the two sequential biopsies. Data are expressed as per cent per hour.

Muscle phenylalanine kinetic parameters were calculated using both the two- and the three-pool arteriovenous balance models as each model provides unique information regarding leg plasma (two-pool) and intracellular (threepool) phenylalanine kinetics [1]. The models' assumptions and validation have been extensively reviewed [24]. The two- and three-pool model parameters were calculated as previously described [11]. Phenylalanine utilisation for protein synthesis and release from breakdown during hyperinsulinaemia were corrected by changes in the intracellular phenylalanine concentration as previously described [25].

Leg glucose utilisation was calculated as net glucose uptake across the leg:

leg glucose uptake $=\mathrm{BF} \times\left(C_{\mathrm{A}}-C_{\mathrm{V}}\right)$

where $\mathrm{BF}$ is the blood flow, and $C_{\mathrm{A}}$ and $C_{\mathrm{V}}$ are the arterial and venous concentrations, respectively.

Changes in blood flow can affect insulin concentration during exogenous infusion. Moreover, insulin recycling from the systemic circulation can increase insulin delivery to the leg. Thus, we calculated the total insulin delivery rate to the leg [10] as follows:

insulin delivery $=\operatorname{Ins}_{\mathrm{FV}} \times \mathrm{BF}$

We used the femoral insulin concentration $\left(\operatorname{Ins}_{\mathrm{FV}}\right)$ in the calculation because arterial insulin concentration was not measurable as the arterial catheter was used for insulin infusion. Because some insulin is cleared by the muscle tissue [26], this method may slightly underestimate the total insulin delivery rate. Nonetheless it provides an additional means to evaluate the degree of muscle insulinisation.

Statistical analysis Statistical analysis was performed using SigmaStat v3.5. Primary outcome measures were blood flow and FSR. Sample size was calculated to detect between group differences of $50 \%$ and $20 \%$ in the change from baseline of FSR and blood flow, respectively, with $\alpha=$ 0.05 and $\beta=0.80$. The Kolmogorov-Smirnov test (with Lilliefors' correction) was used for normality testing. Volunteer's characteristics and baseline values for all measured variables were analysed using the Student's $t$ test or the rank sum test when data failed the normality test. The effect of the insulin dose on the response variables was analysed using ANOVA for repeated measures, the main effects being group (PD, HD) and time (basal, insulin infusion). If the data failed the normality test, log transformation was performed before conducting ANOVA in order to achieve reasonably normal distribution. Pairwise multiple comparisons were performed using the TukeyKramer test. Differences were considered significant at $p<$ 0.05 , with a trend at $p<0.10$.

\section{Results}

Blood flow Leg blood flow was not different between groups at baseline and increased significantly only in the HD group $(p<0.01)$ with a power of 0.86 (Fig. 1). The change in blood flow in the HD group was comparable with that observed in younger individuals during a postprandial insulin infusion.

Insulin and glucose Systemic and femoral vein insulin concentrations were not different at baseline; they were significantly increased in both groups during insulin infusion $(p<0.0001)$, but the change was larger in the HD group $(p<0.05)$ (Table 2$)$. Insulin delivery to the leg was
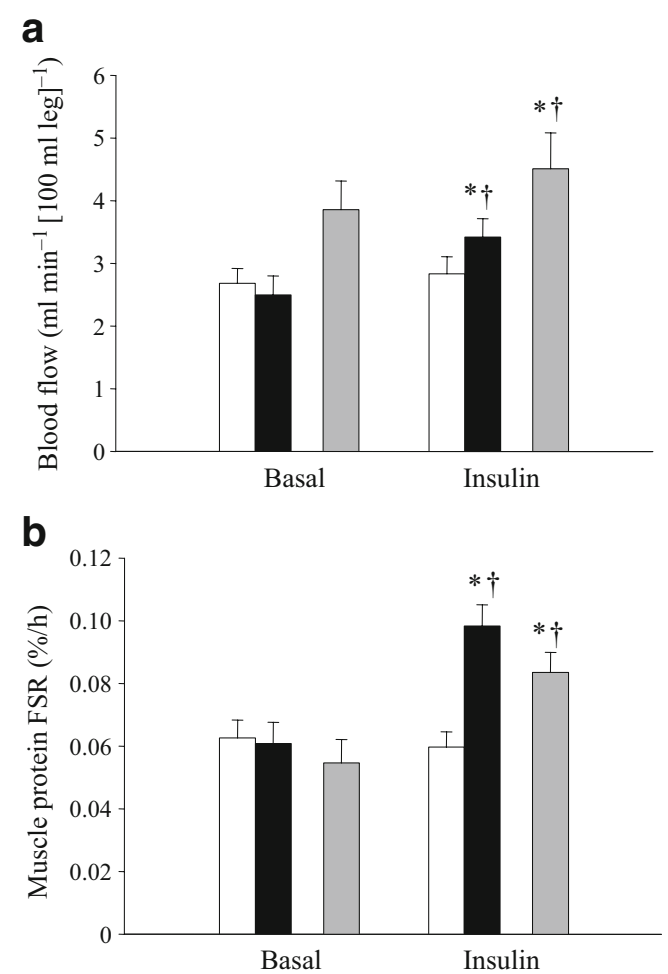

Fig. 1 Blood flow and muscle protein FSR in older volunteers at baseline and during the intra-arterial infusion of insulin at two different rates, which were chosen to increase the femoral vein insulin concentrations to either a postprandial level (PD: $n=8$; white bars) or a supraphysiologically high level (HD: $n=6$; black bars). Data from a group of younger BMI-matched individuals $(n=7$, age $31 \pm$ 2 years), undergoing an insulin infusion at postprandial dose are also reported (grey bars). Values are the means \pm SE. ${ }^{*} p<0.05$ vs basal; ${ }^{\dagger} p<0.01$ vs PD 
Table 2 Insulin and glucose concentrations and leg kinetics in two groups of healthy older volunteers undergoing a local insulin infusion in one leg at postprandial or high dose

\begin{tabular}{|c|c|c|c|c|c|c|c|}
\hline \multirow[t]{2}{*}{ Measurement } & \multicolumn{2}{|c|}{ Postprandial dose } & \multicolumn{2}{|c|}{ High dose } & \multicolumn{3}{|c|}{ ANOVA ( $p$ value) } \\
\hline & Basal & Insulin & Basal & Insulin & Group & Time & Interaction \\
\hline \multicolumn{8}{|l|}{ Insulin } \\
\hline Systemic concentration (pmol/1) & $53 \pm 9$ & $149 \pm 23$ & $37 \pm 9$ & $190 \pm 21$ & 0.57 & $<0.0001$ & 0.07 \\
\hline Femoral vein concentration (pmol/l) & $53 \pm 9$ & $552 \pm 42$ & $37 \pm 9$ & $920 \pm 155$ & 0.03 & $<0.0001$ & 0.02 \\
\hline Delivery to the leg $\left(\mathrm{pmol} \mathrm{min}^{-1}\left[\begin{array}{lll}100 \mathrm{ml} \mathrm{leg}\end{array}\right]^{-1}\right)$ & $134 \pm 24$ & $1,493 \pm 61$ & $90 \pm 23$ & $3,085 \pm 535$ & $<0.01$ & $<0.0001$ & $<0.01$ \\
\hline \multicolumn{8}{|l|}{ Glucose } \\
\hline Arterial concentration $(\mathrm{mmol} / \mathrm{l})$ & $4.8 \pm 0.2$ & $4.6 \pm 0.2$ & $5.2 \pm 0.2$ & $5.0 \pm 0.2$ & 0.28 & 0.18 & 0.54 \\
\hline Infusion rate $\left(\mu \mathrm{mol} \mathrm{kg}{ }^{-1} \min ^{-1}\right)$ & & $11.5 \pm 1.0$ & & $16.9 \pm 1.3$ & $<0.01$ & & \\
\hline Leg uptake $\left(\mu \mathrm{mol} \mathrm{min} \min ^{-1}\left[\begin{array}{ll}100 \mathrm{ml} \mathrm{leg}\end{array}\right]^{-1}\right)$ & & $1.8 \pm 0.4$ & & $3.5 \pm 0.5$ & 0.01 & & \\
\hline
\end{tabular}

Data are means \pm SEM

not different between groups at baseline and it increased significantly during insulin infusion in both groups $(p<$ $0.0001)$, with a larger effect $(p<0.01)$ in the HD group.

Plasma arterial glucose concentrations were not different between groups at baseline and did not change during insulin infusion with euglycaemic clamp. However, the exogenous glucose infusion rate and leg glucose uptake during insulin infusion were significantly higher in the HD group $(p<0.05)$.

Phenylalanine concentrations and enrichments Phenylalanine concentrations in the artery, in the vein and in the muscle were not different at baseline, and were slightly but significantly decreased in both groups during insulin infusion $(p<0.05)$, with no differences between groups (Table 3). Phenylalanine enrichments in the femoral artery and vein and in the muscle tissue were not different between groups in the basal period, and were at steady state during both sampling periods (data not shown). Phenylalanine enrichment in the femoral artery, vein and muscle increased slightly but significantly $(p<0.05)$ during insulin infusion in both groups, with no group differences.
Mixed muscle FSR Mixed muscle protein FSR (\%/h) was not different between groups in the basal state and during insulin infusion was significantly increased in the HD group only $(p<0.05)$ with a power of 0.83 (Fig. 1). The change in mixed muscle FSR in the HD group was comparable with that observed in younger volunteers during a postprandial insulin infusion.

Akt and mTOR signalling For all five selected proteins, the baseline phosphorylation status was not different between groups and the total protein content did not change over time in either group. Akt/PKBSer ${ }^{473}$ phosphorylation increased significantly with insulin (time effect $p<0.01$ ), but the response tended to be greater in the HD group ( $p=0.07)$ (Fig. 2). $\mathrm{mTOR}^{\mathrm{Ser} 248}$ phosphorylation did not increase with insulin $(p=0.12)$ with no significant group effect or interaction. S6K1 $1^{\text {Thr389 }}$ phosphorylation increased significantly with insulin only in the HD group $(p<0.05)$ with a significant difference between groups $(p<0.05)$. 4EBP $1^{\text {Thr37/46 }}$ phosphorylation and eEF2 ${ }^{\mathrm{Thr} 56}$ phosphorylation did not change with insulin in either group, with no difference between groups.
Table 3 Phenylalanine concentrations and enrichments at baseline and during insulin infusion in two groups of healthy older volunteers undergoing a local insulin infusion in one leg at postprandial or high dose

Data are means \pm SEM

\begin{tabular}{|c|c|c|c|c|c|c|c|}
\hline \multirow[t]{2}{*}{ Phenylalanine } & \multicolumn{2}{|c|}{ Postprandial dose } & \multicolumn{2}{|c|}{ High dose } & \multicolumn{3}{|c|}{ ANOVA ( $p$ value) } \\
\hline & Basal & Insulin & Basal & Insulin & Group & Time & Interaction \\
\hline \multicolumn{8}{|c|}{ Concentration $(\mu \mathrm{mol} / \mathrm{l})$} \\
\hline Femoral artery & $60 \pm 2$ & $55 \pm 1$ & $61 \pm 3$ & $57 \pm 4$ & 0.68 & $<0.001$ & 0.39 \\
\hline Femoral vein & $66 \pm 2$ & $55 \pm 1$ & $68 \pm 3$ & $55 \pm 4$ & 0.81 & $<0.0001$ & 0.12 \\
\hline Muscle tissue & $88 \pm 6$ & $66 \pm 6$ & $81 \pm 5$ & $72 \pm 4$ & 0.90 & $<0.01$ & 0.22 \\
\hline \multicolumn{8}{|c|}{ Enrichment (tracer/tracee ratio [\%]) } \\
\hline Femoral artery & $9.2 \pm 0.2$ & $10.3 \pm 0.2$ & $9.7 \pm 0.2$ & $10.4 \pm 0.2$ & 0.70 & $<0.001$ & 0.33 \\
\hline Femoral vein & $6.7 \pm 0.1$ & $8.1 \pm 0.1$ & $7.0 \pm 0.1$ & $8.5 \pm 0.1$ & 0.64 & $<0.01$ & 0.77 \\
\hline Muscle tissue & $5.2 \pm 0.3$ & $6.2 \pm 0.3$ & $5.9 \pm 0.4$ & $6.7 \pm 0.4$ & 0.27 & $<0.05$ & 0.81 \\
\hline
\end{tabular}


Fig. 2 Phosphorylation of Akt/ PKB, S6K1, 4E-BP1 and eEF2 in older volunteers at baseline and during the intra-arterial infusion of insulin at two different rates, chosen to increase the femoral vein insulin concentrations to either a postprandial level (PD: $n=6$ for Akt/PKB and $\mathrm{S} 6 \mathrm{~K} 1 ; n=5$ for 4E-BP1 and eEF2; white bars) or a supraphysiologically high level (HD: $n=6$ for all proteins; black bars). Values are the mean $\pm \mathrm{SE}$. ${ }^{*} p<0.05$ vs basal; ${ }^{\dagger} p=0.07$ vs PD; ${ }^{\S} p<0.05$ vs PD. AU, absorbance unit a

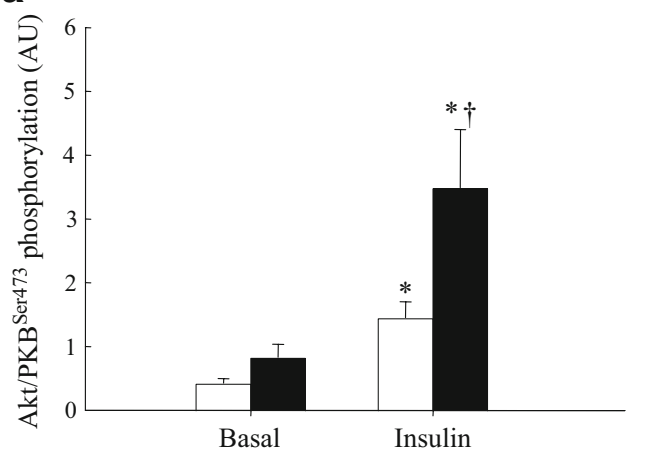

C

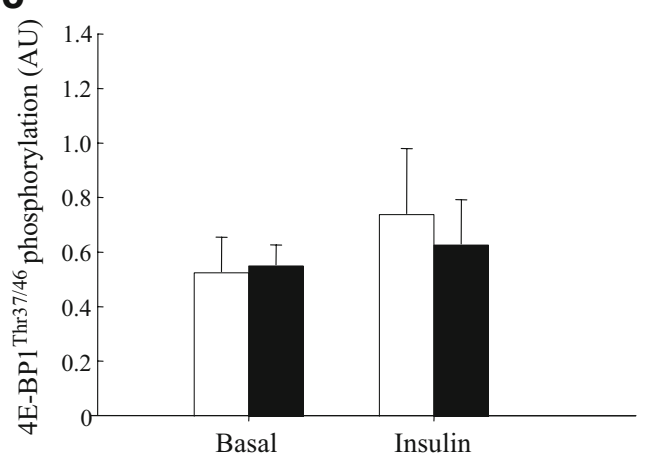

b

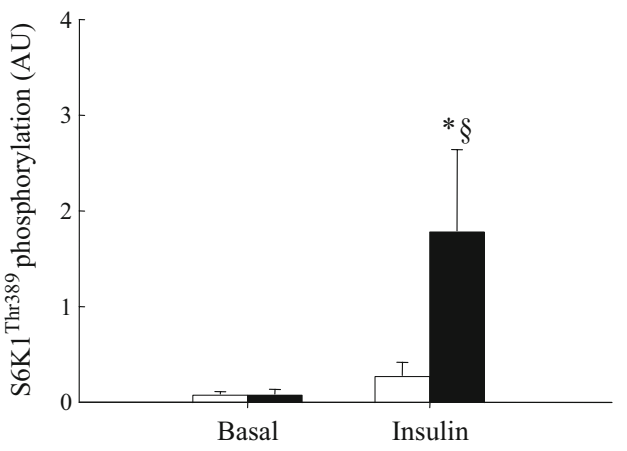

d

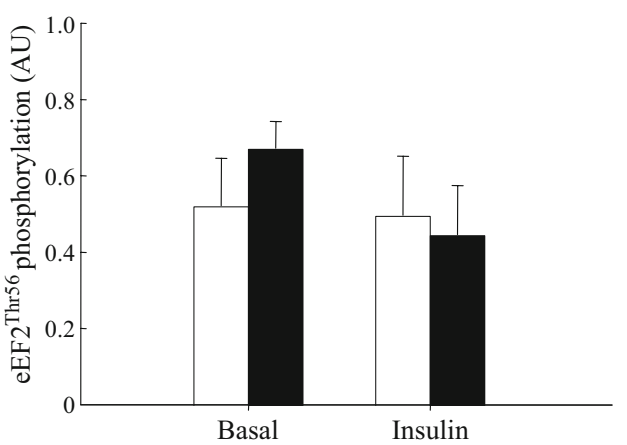

Phenylalanine kinetics None of the phenylalanine kinetic variables were significantly different between groups in the basal period (Table 4). With insulin infusion, phenylalanine delivery to and release from the leg increased in the HD group only $(p<0.05)$. A significant interaction was found for phenylalanine release from the leg, which tended to increase in the HD group while decreasing from basal in the PD group.

There was a time effect $(p<0.05)$ for phenylalanine release in blood from proteolysis (leg rate of appearance) due to a significant decrease in the PD group $(p<0.05)$ with no change in the HD group. In contrast, there was a trend $(p=0.06)$ for a time by group interaction for phenylalanine disappearance from the blood (leg rate of disappearance), an index of protein synthesis, because of a significant increase in the HD group only $(p<0.05)$.

Phenylalanine transport into the muscle free pool and intracellular availability did not change significantly with insulin, whereas phenylalanine transport from the muscle free pool into the venous blood decreased in both groups $(p<0.05)$.

Table 4 Phenylalanine kinetics at baseline and during insulin infusion in two groups of healthy older volunteers undergoing a local insulin infusion in one leg at postprandial or high dose

\begin{tabular}{|c|c|c|c|c|c|c|c|}
\hline \multirow[t]{2}{*}{ Measurement ${ }^{\mathrm{a}}$} & \multicolumn{2}{|c|}{ Postprandial dose } & \multicolumn{2}{|c|}{ High dose } & \multicolumn{3}{|c|}{ ANOVA } \\
\hline & Basal & Insulin & Basal & Insulin & Group & Time & Interaction \\
\hline Delivery to the leg & $160 \pm 12$ & $154 \pm 12$ & $150 \pm 17$ & $195 \pm 21$ & 0.39 & 0.03 & 0.02 \\
\hline Release from the leg & $175 \pm 13$ & $155 \pm 11$ & $167 \pm 16$ & $186 \pm 20$ & 0.50 & 0.95 & 0.05 \\
\hline Net balance across the leg & $-15 \pm 2$ & $-1 \pm 3$ & $-17 \pm 2$ & $9 \pm 4$ & 0.17 & $<0.0001$ & 0.04 \\
\hline Release in blood from proteolysis & $62 \pm 8$ & $46 \pm 8$ & $55 \pm 3$ & $46 \pm 7$ & 0.80 & $<0.01$ & 0.47 \\
\hline Disappearance from the blood & $46 \pm 8$ & $45 \pm 8$ & $38 \pm 5$ & $55 \pm 7$ & 0.88 & 0.10 & 0.06 \\
\hline Transport into muscle free pool & $115 \pm 17$ & $88 \pm 15$ & $103 \pm 10$ & $115 \pm 20$ & 0.45 & 0.80 & 0.26 \\
\hline Transport from muscle free pool & $130 \pm 18$ & $88 \pm 13$ & $120 \pm 8$ & $106 \pm 22$ & 0.70 & 0.02 & 0.23 \\
\hline Release from muscle proteolysis & $70 \pm 8$ & $61 \pm 12$ & $62 \pm 5$ & $61 \pm 10$ & 0.76 & 0.50 & 0.57 \\
\hline Utilisation for muscle protein synthesis & $55 \pm 7$ & $59 \pm 11$ & $45 \pm 7$ & $71 \pm 11$ & 0.94 & 0.04 & 0.05 \\
\hline Intracellular availability & $185 \pm 23$ & $148 \pm 23$ & $166 \pm 12$ & $176 \pm 26$ & 0.75 & 0.48 & 0.16 \\
\hline
\end{tabular}

Data are means \pm SEM. ${ }^{\text {a } U n i t s ~ a r e ~} \mathrm{nmol} \mathrm{min}^{-1}(100 \mathrm{ml} \mathrm{leg})^{-1}$ 
Phenylalanine release from muscle proteolysis did not change significantly with insulin in either group. There was a significant time effect and time by group interaction for phenylalanine utilisation for muscle protein synthesis, which increased significantly during insulin infusion only in the HD group $(p<0.05)$. Net phenylalanine balance across the leg improved in both groups in response to insulin $(p<$ 0.0001 ), but the increase was significantly greater in HD such that net balance became positive only in the HD group $(p<0.01)$, indicating net muscle protein anabolism.

\section{Discussion}

The results of this study indicate for the first time that skeletal muscle protein metabolism is truly insulin resistant in healthy, glucose-tolerant older adults. Specifically, we found in healthy older persons that supraphysiological hyperinsulinaemia was necessary to stimulate mixed muscle protein synthesis and net muscle protein anabolism while, consistent with previously published data $[8,10,11]$, hyperinsulinaemia within the physiological postprandial range had only minor effects on muscle protein metabolism. Improvements in muscle protein anabolism observed with supraphysiological hyperinsulinaemia were associated with enhanced amino acid delivery, induced by increased leg blood flow, and enhanced Akt/PKB and S6K1 signalling. When we compare the effects of the two insulin doses on protein synthesis and blood flow in our elderly individuals with those obtained in BMI-matched healthy younger individuals with physiological hyperinsulinaemia (Fig. 1), it is clear that healthy older adults require double the insulin dose in order to increase muscle protein synthesis and vasodilatation to levels normally achieved by younger individuals during postprandial hyperinsulinaemia. A fascinating aspect of these results is that despite some analogies with the classic insulin resistance of glucose metabolism as observed in type 2 diabetes, the mechanisms underlying insulin resistance of muscle protein metabolism with ageing are probably different.

First, our volunteers, although overweight, had a normal glucose tolerance as assessed at screening, and exhibited a leg glucose uptake proportional to the insulin dose and consistent with uptakes previously reported in younger healthy individuals under comparable experimental conditions $[1,10]$. Moreover, while volunteers in the HD group tended to be heavier than those in the PD group, they responded positively to insulin. Thus, if adiposity had a negative impact on the muscle protein anabolic response to insulin, it would have led to underestimation of the effect of the high insulin dose on skeletal muscle protein anabolism. Furthermore, we have previously shown that type 2 diabetes and excess adiposity do not influence the acute response of skeletal muscle protein synthesis and anabolism in younger individuals [9], and we report here that blood flow and muscle protein synthesis are stimulated by a postprandial insulin dose in younger overweight individuals. Others have reported that the degree of glucose control does not affect skeletal muscle protein synthesis in type 2 diabetic patients [27]. Thus, it is becoming apparent that the age-related insulin resistance of muscle proteins and the classic insulin resistance of glucose metabolism leading to type 2 diabetes are two independent conditions, although they may share some characteristics.

Second, these results and others $[1,10,11]$ suggest that the vasodilatory effect of insulin plays a much larger role in the modulation and stimulation of muscle protein anabolism in young and older individuals compared with its effect on glucose metabolism, for which it appears to be rate limiting only when glucose uptake is elevated and the artery-to-vein glucose concentration gradient is high [2830]. An increase in microvascular recruitment increases the amount of tissue perfused and amino acid delivery to the muscle even in the presence of small decreases in amino acid concentrations, as occurred in the HD group of this study and in previous studies [1, 10, 11]. This interplay between insulin vasodilatation and amino acid availability appears to be an essential component of the overall anabolic effect of insulin. In fact, when profound hypoaminoacidaemia is induced with a systemic insulin infusion in the absence of amino acid replacement [7, 20, 31-33], amino acid delivery to the muscle will be reduced and the insulin anabolic effect will be mainly ascribed to reduced protein breakdown, rather than an increase in synthesis. However, if amino acids concentrations are maintained during a systemic insulin infusion, then insulin has a protein anabolic effect on human skeletal muscle [4, 6-8, 33, 34]. On the other hand, if amino acid concentrations are greatly increased to high postprandial levels using mixtures containing large amounts of arginine, the anabolic effect of insulin on protein synthesis may be masked by significant amino acid-induced increases in blood flow [35]. Consistent with previous reports [10, 11, 36], we found that physiological elevations in blood insulin were unable to increase blood flow in elderly individuals. However, we also found that supraphysiological hyperinsulinaemia induced a significant increase in blood flow, and this effect was associated with stimulation of muscle protein synthesis and net anabolism. It has been shown that the first effect of insulin is a rapid, nitric oxide-dependent microvascular recruitment that precedes increases in total blood flow and the effects on intracellular signalling and glucose uptake in muscle [37]. Although we did not directly measure capillary recruitment, it is likely that the differential effects of the two insulin doses on total leg blood flow were accompanied by concomitant differential 
effects on muscle perfusion, with the higher dose being the only one able to stimulate microvascular recruitment. It is thus conceivable that the age-related endothelial dysfunction may limit the insulin-induced increase in nutrient flow, amino acid uptake and, consequently, muscle protein synthesis. Impaired endothelial-dependent capillary recruitment may also be responsible for the suboptimal anabolic response to mixed feeding in older persons [12], as lack of vasodilation reduces the amount of muscle tissue perfused and, consequently, nutrient and hormone delivery. On the other hand, perfusion alone may not be the only limiting factor. Recent data suggest that insulin transport across the endothelium into the muscle is a saturable process requiring intact insulin signalling, and it can therefore be an important regulator of insulin availability and action [26, 38].

Third, the muscle cell signalling data also suggest a relative insulin resistance, which may be related to both endothelial dysfunction and anabolic resistance to the insulin stimulus. While the group receiving the postprandial insulin dose was able to increase $\mathrm{Akt} / \mathrm{PKB}^{\mathrm{Ser} 473}$ phosphorylation (although to a lesser extent than the group receiving the supraphysiological insulin dose), it was incapable of increasing the phosphorylation and, presumably, the activity of downstream effectors known to regulate translation initiation and protein synthesis in skeletal muscle. In particular, in our older volunteers supraphysiological hyperinsulinaemia was capable of increasing the phosphorylation state of $\mathrm{S} 6 \mathrm{~K} 1^{\mathrm{Thr} 389}$ whereas, consistent with previous reports [8, 11], insulin concentrations in the normal physiological range did not. It should be kept in mind that the phosphorylation status of our selected proteins was measured at baseline and again $3 \mathrm{~h}$ after the initiation of the insulin clamp. Therefore, because physiological hyperinsulinaemia increased $\mathrm{Akt} / \mathrm{PKB}^{\mathrm{Ser} 473}$ phosphorylation, it is possible that phosphorylation of $\mathrm{mTOR}^{\mathrm{Ser} 2448}$ and S6K $1^{\text {Thr389 }}$ increased to some extent at earlier time points during the insulin clamp, but had returned to baseline values when we obtained the last muscle sample. On the other hand, supraphysiological hyperinsulinaemia in the older volunteers induced a much greater increase in Akt/ $\mathrm{PKB}^{\mathrm{Ser} 473}$ phosphorylation, thus resulting in a sustained phosphorylation of S6K1 $1^{\text {Thr389 }}$ and a significant increase in the rate of muscle protein synthesis. This is consistent with the notion that supraphysiological hyperinsulinaemia is capable of overriding the insulin resistance of protein metabolism in older individuals.

While these results are very exciting and may add another important piece of understanding to the complex sarcopenia puzzle, generalisation to the entire population should be done cautiously. The complexity and invasiveness of the methods used to measure muscle protein metabolism is limiting with regards to sample size. For example, only three older women were included in this study. It is still unclear whether sex has a significant effect on muscle protein turnover in young and older adults, since some studies have reported baseline differences [39, 40] while others show no effect [41-44]. Nonetheless, a recent study suggests that there is no sexual dimorphism in the response of muscle proteins to insulin [44]. Thus, while with the current data we cannot draw conclusions regarding the effect of sex on the muscle protein response to insulin in older people, we believe that our results obtained from men and women are valid.

In conclusion, our data provide for the first time evidence that skeletal muscle protein metabolism is insulin resistant in healthy, non-diabetic older persons, as protein anabolism can be elicited only by supraphysiological hyperinsulinaemia. This defect appears unrelated to glucose tolerance and associated with endothelial dysfunction and blunted anabolic signalling, although the relative importance of these two complex mechanisms is still unclear and warrants further investigation. Insulin resistance of muscle protein metabolism with ageing may be a contributor to the development of sarcopenia in older adults as it may decrease the physiological muscle anabolic response to feeding [12], thereby inducing a slow but progressive decline in muscle protein content. Future mechanistic studies will be necessary to clearly determine the role and contribution of insulin resistance and endothelial dysfunction to muscle loss in older people.

Acknowledgements We wish to thank the study volunteers, $M$. Zheng for superb technical assistance and J. D. Cadenas and the nurses and personnel of the UTMB and USC General Clinical Research Centers for their assistance with the clinical conduct of this study. This study was supported by grants no. R01 AG18311 and the UTMB Claude D. Pepper Older Americans Independence Center no. P30 AG024832 from the National Institute on Aging, National Institutes of Health (NIH); grant no. S10 RR16650 from the Shared Instrumentation Grant Program, National Center for Research Resources, NIH; General Clinical Research Center grants no. M01 RR00043 (USC) and M01 RR00073 (UTMB), and grant no. S10 RR16650 from the National Center for Research Resources, NIH.

Duality of interest The authors declare that there is no duality of interest associated with this manuscript.

\section{References}

1. Fujita S, Rasmussen BB, Cadenas JG, Grady JJ, Volpi E (2006) The effect of insulin on human skeletal muscle protein synthesis is modulated by insulin-induced changes in muscle blood flow and amino acid availability. Am J Physiol Endocrinol Metab 291: E745-E754

2. Bennet WM, Connacher AA, Scrimgeour CM, Jung RT, Rennie MJ (1990) Euglycemic hyperinsulinemia augments amino acid uptake by leg tissues during hyperaminoacidemia. Am J Physiol 259:E185-E194 
3. Biolo G, Declan Fleming RY, Wolfe RR (1995) Physiologic hyperinsulinemia stimulates protein synthesis and enhances transport of selected amino acids in human skeletal muscle. J Clin Invest 95:811-819

4. Newman E, Heslin MJ, Wolf RF, Pisters PW, Brennan MF (1994) The effect of systemic hyperinsulinemia with concomitant amino acid infusion on skeletal muscle protein turnover in the human forearm. Metabolism 43:70-78

5. Wolf RF, Heslin MJ, Newman E, Pearlstone DB, Gonenne A, Brennan MF (1992) Growth hormone and insulin combine to improve whole-body and skeletal muscle protein kinetics. Surgery 112:284-291 discussion 291-292

6. Hillier TA, Fryburg DA, Jahn LA, Barrett EJ (1998) Extreme hyperinsulinemia unmasks insulin's effect to stimulate protein synthesis in the human forearm. Am J Physiol 274:E1067-E1074

7. Nygren J, Nair KS (2003) Differential regulation of protein dynamics in splanchnic and skeletal muscle beds by insulin and amino acids in healthy human subjects. Diabetes 52(6):13771385

8. Guillet C, Prod'homme M, Balage M et al (2004) Impaired anabolic response of muscle protein synthesis is associated with S6K1 dysregulation in elderly humans. FASEB J 18(13):15861587

9. Bell JA, Volpi E, Fujita S, Cadenas JG, Sheffield-Moore M, Rasmussen BB (2006) Skeletal muscle protein anabolic response to increased energy and insulin is preserved in poorly controlled type 2 diabetes. J Nutr 136:1249-1255

10. Rasmussen BB, Fujita S, Wolfe RR et al (2006) Insulin resistance of muscle protein metabolism in aging. FASEB J 20:768-769

11. Fujita S, Rasmussen BB, Cadenas JG et al (2007) Aerobic exercise overcomes the age-related insulin resistance of muscle protein metabolism by improving endothelial function and akt/ mammalian target of rapamycin signaling. Diabetes 56:16151622

12. Volpi E, Mittendorfer B, Rasmussen BB, Wolfe RR (2000) The response of muscle protein anabolism to combined hyperaminoacidemia and glucose-induced hyperinsulinemia is impaired in the elderly. J Clin Endocrinol Metab 85:4481-4490

13. Rieu I, Balage M, Sornet C et al (2006) Leucine supplementation improves muscle protein synthesis in elderly men independently of hyperaminoacidaemia. J Physiol (Lond) 575:1-15

14. Fried LP, Hadley EC, Walston JD et al (2005) From bedside to bench: research agenda for frailty. Sci Aging Knowledge Environ 2005:e24

15. Janssen I, Shepard DS, Katzmarzyk PT, Roubenoff R (2004) The healthcare costs of sarcopenia in the United States. J Am Geriatr Soc 52:80-85

16. Bell JA, Fujita S, Volpi E, Cadenas JG, Rasmussen BB (2005) Short-term insulin and nutritional energy provision does not stimulate muscle protein synthesis if blood amino acid availability decreases. Am J Physiol Endocrinol Metab 289:999-1006

17. Jorfeldt L, Juhlin-Dannfelt A (1978) The influence of ethanol on splanchnic and skeletal muscle metabolism in man. Metabolism 27:97-106

18. Jorfeldt L, Wahren J (1971) Leg blood flow during exercise in man. Clin Sci 41:459-473

19. Wolfe RR (1992) Radioactive and stable isotope tracers in biomedicine. Principles and practice of kinetic analysis. WileyLiss, New York

20. Denne SC, Liechty EA, Liu YM, Brechtel G, Baron AD (1991) Proteolysis in skeletal muscle and whole body in response to euglycemic hyperinsulinemia in normal adults. Am J Physiol 261: E809-E814

21. Calder AG, Anderson SE, Grant I, McNurlan MA, Garlick PJ (1992) The determination of low d5-phenylalanine enrichment (0.002-0.09 atom percent excess), after conversion to phenyleth- ylamine, in relation to protein turnover studies by gas chromatography/electron ionization mass spectrometry. Rapid Commun Mass Spectrom 6:421-424

22. Dreyer HC, Fujita S, Cadenas JG, Chinkes DL, Volpi E, Rasmussen BB (2006) Resistance exercise increases AMPK activity and reduces 4E-BP1 phosphorylation and protein synthesis in human skeletal muscle. J Physiol (Lond) 576:2-24

23. Toffolo G, Foster DM, Cobelli C (1993) Estimation of protein fractional synthetic rate from tracer data. Am J Physiol 264:E128 E135

24. Wolfe RR, Chinkes DL (2004) Isotope tracers in metabolic research: principles and practice of kinetic analysis, 2nd edn. Wiley, Hoboken

25. Katsanos CS, Chinkes DL, Sheffield-Moore M, Aarsland A, Kobayashi H, Wolfe RR (2005) Method for the determination of the arteriovenous muscle protein balance during non-steady-state blood and muscle amino acid concentrations. Am J Physiol Endocrinol Metab 289:E1064-E1070

26. Eggleston EM, Jahn LA, Barrett EJ (2007) Hyperinsulinemia rapidly increases human muscle microvascular perfusion but fails to increase muscle insulin clearance: evidence that a saturable process mediates muscle insulin uptake. Diabetes 56:2958-2963

27. Halvatsiotis P, Short KR, Bigelow M, Nair KS (2002) Synthesis rate of muscle proteins, muscle functions, and amino acid kinetics in type 2 diabetes. Diabetes 51:2395-2404

28. Baron AD, Tarshoby M, Hook G et al (2000) Interaction between insulin sensitivity and muscle perfusion on glucose uptake in human skeletal muscle: evidence for capillary recruitment. Diabetes 49(5):768-774

29. Vincent MA, Clerk LH, Lindner JR et al (2004) Microvascular recruitment is an early insulin effect that regulates skeletal muscle glucose uptake in vivo. Diabetes 53:1418-1423

30. Clerk LH, Vincent MA, Lindner JR, Clark MG, Rattigan S, Barrett EJ (2004) The vasodilatory actions of insulin on resistance and terminal arterioles and their impact on muscle glucose uptake. Diabetes/Metabolism Research Reviews 20:312

31. Tessari P, Inchiostro S, Biolo G, Vincenti E, Sabadin L (1991) Effects of acute systemic hyperinsulinemia on forearm muscle proteolysis in healthy man. J Clin Invest 88:27-33

32. De Feo P, Volpi E, Lucidi P et al (1993) Physiological increments in plasma insulin concentrations have selective and different effects on synthesis of hepatic proteins in normal humans. Diabetes 42:995-1002

33. Moller-Loswick AC, Zachrisson H, Hyltander A, Korner U, Matthews DE, Lundholm K (1994) Insulin selectively attenuates breakdown of nonmyofibrillar proteins in peripheral tissues of normal men. Am J Physiol 266:E645-E652

34. Heslin MJ, Newman E, Wolf RF, Pisters PW, Brennan MF (1992) Effect of hyperinsulinemia on whole body and skeletal muscle leucine carbon kinetics in humans. Am J Physiol 262: E911-E918

35. Greenhaff PL, Karagounis LG, Peirce N et al (2008) Disassociation between the effects of amino acids and insulin on signaling, ubiquitin ligases, and protein turnover in human muscle. Am J Physiol Endocrinol Metab 295:E595-E604

36. Meneilly GS, Elliot T, Bryer-Ash M, Floras JS (1995) Insulinmediated increase in blood flow is impaired in the elderly. J Clin Endocrinol Metab 80:1899-1903

37. Vincent MA, Dawson D, Clark AD et al (2002) Skeletal muscle microvascular recruitment by physiological hyperinsulinemia precedes increases in total blood flow. Diabetes 51(1):42-48

38. Wang H, Wang AX, Liu Z, Barrett EJ (2008) Insulin signaling stimulates insulin transport by bovine aortic endothelial cells. Diabetes 57:540-547 
39. Smith GI, Atherton P, Villareal DT et al (2008) Differences in muscle protein synthesis and anabolic signaling in the postabsorptive state and in response to food in 65-80 year old men and women. PLoS ONE 3:e1875

40. Henderson GC, Dhatariya K, Ford GC et al (2009) Higher muscle protein synthesis in women than men across the lifespan, and failure of androgen administration to amend age-related decrements. FASEB J 23:631-641

41. Parise G, Mihic S, MacLennan D, Yarasheski KE, Tarnopolsky MA (2001) Effects of acute creatine monohydrate supplementation on leucine kinetics and mixed-muscle protein synthesis. J Appl Physiol 91:1041-1047
42. Balagopal P, Rooyackers OE, Adey DB, Ades PA, Nair KS (1997) Effects of aging on in vivo synthesis of skeletal muscle myosin heavy-chain and sarcoplasmic protein in humans. Am J Physiol Endocrinol Metab 273:E790-E800

43. Fujita S, Rasmussen BB, Bell JA, Cadenas JG, Volpi E (2007) Basal muscle intracellular amino acid kinetics in women and men. Am J Physiol Endocrinol Metab 292:E77-E83

44. Smith GI, Reeds DN, Mohammed BS, Jaffery H, Mittendorfer B (2009) The basal rate of muscle protein synthesis and its response to hyperinsulinemia-hyperaminoacidemia are the same in young men and women. FASEB J 23:991.23 (Abstract) 